\title{
Theoretical Study of Transverse Offsets of Wide Span Tractor Working Implements and Their Influence on Damage to Row Crops
}

\author{
Volodymyr Bulgakov $^{1}$, Simone Pascuzzi ${ }^{2, *} \mathbb{C}$, Valerii Adamchuk ${ }^{3}$, Volodymyr Kuvachov ${ }^{4}$ and \\ Ladislav Nozdrovicky ${ }^{5}$ \\ 1 Department of Mechanics, Faculty of Design and Engineering, National University of Life and \\ Environmental Sciences of Ukraine, Heroyiv Oborony 15, 03041 Kyiv, Ukraine \\ 2 Department of Agricultural and Environmental Science, University of Bari Aldo Moro, Via Amendola 165/A, \\ 70126 Bari, Italy \\ 3 National Scientific Centre “Institute for Agricultural Engineering and Electrification", Vokzalna 1, \\ 1108631 Glevaha, Ukraine \\ 4 Department of Machine use in crop production, Mechanical and Technological Faculty, Tavria State \\ Agrotechnological University, Khmelnytskiy av. 18, 72312 Melitopol, Zaporozhye Region, Ukraine \\ 5 Department of Machines and Production Biosystems, Faculty of Engineering, Slovak University of \\ Agriculture in Nitra, Trieda Andreja Hlinku 2, 94976 Nitra, Slovakia \\ * Correspondence: simone.pascuzzi@uniba.it; Tel./Fax: +39-080-544-2214
}

Received: 2 June 2019; Accepted: 4 July 2019; Published: 5 July 2019

\begin{abstract}
Wide span tractors have a wide transversal bar, on which different implements can be mounted, while the supporting wheels follow the set traffic-lanes. The stability of wide span tractor movement is influenced by unbroken small angular deviations and transversal displacements of the machine due to several factors. These deflections from the set trajectories affect the working implements, especially the peripheral ones, which can cut the plants if wide span tractors are used to manage row crops. In this context, it needs to consider a safeguard zone that allows to reduce the probability of contact between working implements and plants. The aim of this paper was to determine the quantitative effect of transverse displacements of the working implements and the suitable size of the aforesaid safeguard zone. The magnitude of the inner and outer displacements of the working implements depends significantly on their location in relation to the center of the wide span tractor. For working implements located outside the center of the tractor, the outer safeguard zone should be larger than the inner zone. The probability of crop damage by working implements can be reduced by automated control of wide span tractor movement.
\end{abstract}

Keywords: controlled traffic farming; wide span tractor; row crop damage; theoretical modeling

\section{Introduction}

In recent years, the aim to improve the efficiency of agricultural operations has increased the size and weight of agricultural machinery and in-field traffic [1], causing greater soil compaction [2-4]. Traffic-induced soil compaction can be avoided using controlled traffic farming (CTF), in which cropping areas are clearly and permanently separated from traffic-lanes [5-7]. With CTF, tractor wheels do not come into contact with the cultivation area, but increasingly compact the traffic-lanes, thus improving draught efficiency [8-11]. Wide span tractors are usually used in CTF because of their undeniable advantages over traditional tractors and machine-and-tractor aggregates [12-15]. This type of tractor can be used in operations from sowing to crop management (mechanical weeding, 
fertilization and so on); it has a wide transversal bar, on which different working implements can be mounted, while the supporting wheels follow the set traffic-lanes [16,17].

Several factors affect the stability of the movements of wide span tractors used in CTF, including the uneven resistance of the soil, the forward speed, and the resistance forces that develop during cornerings [18-20]. The magnitude of these factors changes constantly, causing continual small angular deviations and transversal displacements of the tractor [21]. Furthermore, the track is several times wider than the wheelbase of this type of tractor, so that the angular and transversal deviations cause considerable displacement of the working implements, especially the most peripherical ones, i.e., those farthest from the center of the machine $[19,22]$. When wide span tractors are used to manage row crops, these deflections from the set trajectories mean that the working implements, especially the more peripheral ones, can cut and damage the crop plants. In this case, the operative efficiency of wide span tractors is strictly correlated to the amount of crop plants damaged by the working implements [19,21]. Their transverse deflection must be reduced to a minimum in order to obtain better quality working conditions, although there is no doubt that the accidental non-alignment of plants along the rows also has a significant effect on the amount of the damage caused by these tractors. Therefore, the continual transverse displacements of the wide span tractor and the random non-alignment of the plants along the row increase the probability of working implements damaging the crop plants. In this context, there is a need for a safeguard zone large enough to reduce the probability of contact between tractor implements and crop plants. The aim of this paper was to establish the mathematical relationships concerning the quantitative effect of transverse displacements of the working implements and to evaluate the probability of such contacts within the safeguard zone. Furthermore, it used a statistical approach to assess the size of the safeguard zone that reduces the probability of working implement-plant contact below a set value.

\section{Material and Methods}

\subsection{Kinematic Considerations}

Kinematic analysis was performed on the transverse shifts of the working implements caused by the continuous small angular deviations and transversal displacements of a wide span tractor moving at constant speed along a technological track [23-25]. The wide span tractor system with six implements (coulters) mounted on its transversal bar is shown in Figure 1. The total displacement of each coulter consists of the displacement $X_{S}$ of the center of the wide span tractor (i.e., $S$ in Figure 1) from the set trajectory of motion and its own deflection due to the angular deviation $\varphi$ of the tractor. Obviously, the intensity of total displacement increases together with the distance from the center of the tractor, so that the most peripheral coulter undergoes a more marked deflection (Figure 1).

As for the traditional tractor-implement aggregates, opposite angular deviations of the tractor of the same magnitude produce corresponding "outer" and "inner" deviations of the implement, with different magnitudes [26]. It is likely that the same occurs for wide-span tractors, so that every working implement attached to the wide span of the tractor will be subject to different "outer" and "inner" deviations corresponding to the equal but opposite angular deviations of the tractor.

Considering point $A$ of the coulter (Figure 1), its kinematic "inner" displacement $\alpha_{\varphi}^{i}$ caused by the angular deviation of the wide span tractor can be evaluated with the following (Figure 1) [23,24]:

$$
\alpha_{\varphi}^{i}=x \sin (\gamma+\beta)=x(\sin \gamma \cdot \cos \beta+\cos \gamma \cdot \sin \beta)
$$

where $x=K A=A K_{1}$ (Figure 1)-deviation of the coulter; $\gamma$-angle, depending on the design parameters of wide span tractor $(b, l) ; \beta$-angle, depending on the magnitude of the angular deviation of the wide span tractor.

Similarly, the kinematic "outer" displacement $\alpha_{\varphi}^{e}$ of the coulter is evaluated with the following $[23,24]$ :

$$
\alpha_{\varphi}^{e}=x \cos (\gamma+\beta)=x(\cos \gamma \cdot \cos \beta-\sin \gamma \cdot \sin \beta)
$$




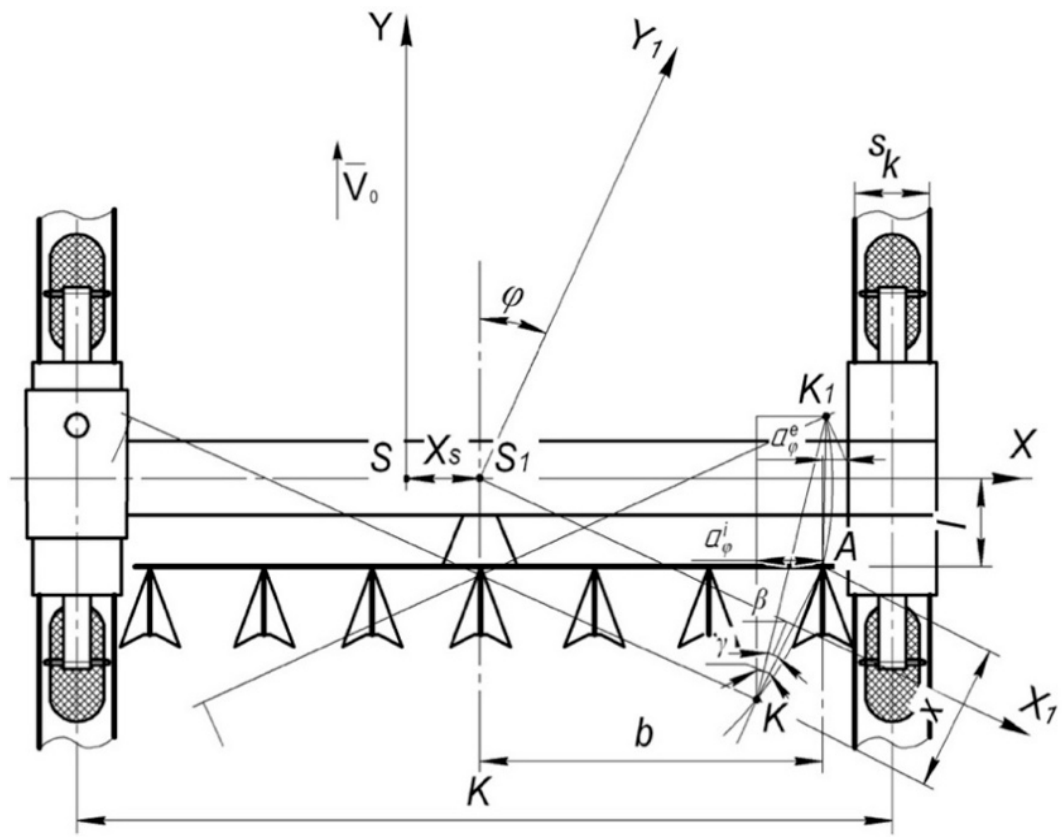

Figure 1. Transverse displacements of the wide span tractor and its working implements (coulters).

\subsection{Statistical Approach}

Considering the wide span tractor in Figure 1 and its uninterrupted small angular deviations and transversal shifts from the set direction during constant motion along a technological track, it is assumed that curves 1 and 2 in Figure 2 represent the respective probability densities of: (i) the transverse displacements of an individual coulter from its set trajectory of movement $Y_{d}-Y_{d}$; (ii) the placements of plants relative to the axis of the row $Y_{r}-Y_{r}$. Segment $Z$ is the zone where there is the probability of the presence of the coulter $p\left(X_{o Z}\right)$ and the probability that plants will be in the coulter's trajectory of movement due to their non-alignment along the row $p\left(X_{r Z}\right)$.

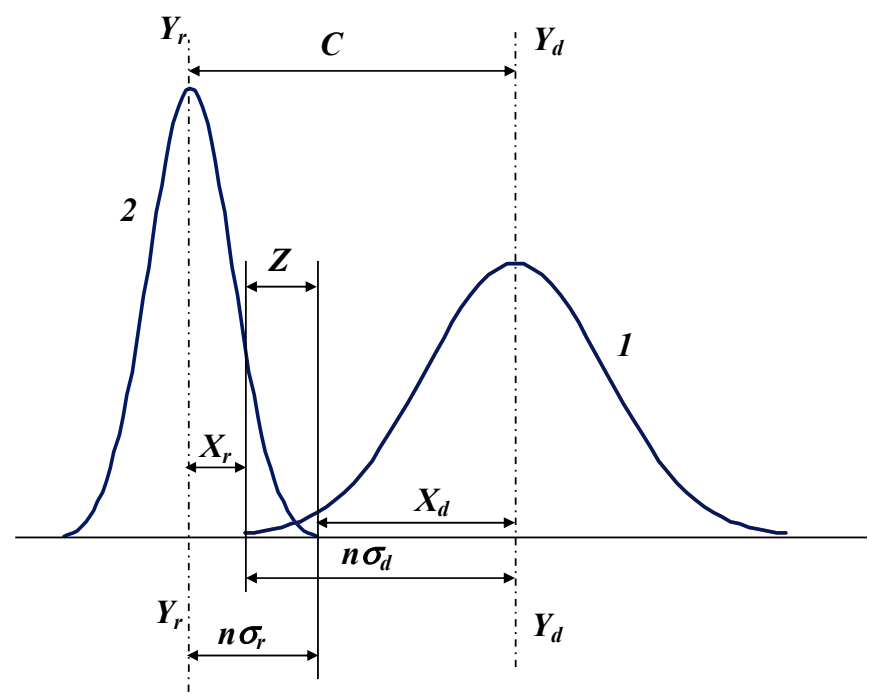

Figure 2. The probability density function of the transverse displacements from the given direction of coulter movement 1 and plant position 2. 
Thus, the probability of plant damage $p\left(D_{Z}\right)$ in zone $Z$ can be evaluated according to the theorem that states the probability of the simultaneous occurrence of two independent events [27]:

$$
p\left(D_{Z}\right)=p\left(X_{o Z} \cdot X_{r Z}\right)=p\left(X_{o Z}\right) \cdot p\left(X_{r Z}\right)
$$

If zone $C$ is sufficiently wide, so that curves 1 and 2 in Figure 2 do not intersect (Figure 2), then zone $Z$ is absent and the coulter causes no plant damage.

The value of the edges for $X_{r}$ and $X_{d}$ of zone $Z$ can be evaluated with the following:

$$
\begin{aligned}
& X_{r}=C-n \sigma_{d} \\
& X_{d}=C-n \sigma_{r}
\end{aligned}
$$

where $\sigma_{d}$ and $\sigma_{r}$, respectively, are the standard deviations of the transverse displacements of the coulter and standard deviations of the different non-aligned positions of plants in the row; $n \sigma_{d}$ and $n \sigma_{r}$ are thelimits of deviations, where the value $n$ can be 3 with sufficient accuracy; $C$ is the value of the safeguard zone. The probability of finding the coulter $p\left(X_{o Z}\right)$ inside zone $Z$ can be assessed with the distribution functions $F_{X_{o Z}}\left(n \sigma_{d}\right)$ and $F_{X_{o Z}}\left(X_{d}\right)$ and the probability density function $f_{X_{o Z}}(u)$ [27]:

$$
\begin{gathered}
p\left(X_{o Z}\right)=p\left(X_{d}<X_{o Z}<n \sigma_{d}\right)=F_{X_{o Z}}\left(n \sigma_{d}\right)-F_{X_{t Z}}\left(X_{d}\right) \\
=\int_{-\infty}^{n \sigma_{d}} f_{X_{o Z}}(u) d u-\int_{-\infty}^{X_{d}} f_{X_{o Z}}(u) d u
\end{gathered}
$$

In a similar way, the probability of finding non-aligned plants in a row $p\left(X_{p Z}\right)$ inside the same zone $Z$ can be evaluated with the distribution functions $F_{X_{p Z}}\left(n \sigma_{r}\right)$ and $F_{X_{p Z}}\left(X_{r}\right)$ and the probability density function $f_{X_{p Z}}(u)$ :

$$
\begin{gathered}
p\left(X_{p Z}\right)=p\left(-n \sigma_{r}<-X_{p Z}<-X_{r}\right)=F_{X_{p Z}}\left(-X_{r}\right)-F_{X_{p Z}}\left(-n \sigma_{r}\right) \\
=\int_{-\infty}^{X_{r}} f_{X_{p Z}}(u) d u-\int_{-\infty}^{n \sigma_{r}} f_{X_{p Z}}(u) d u
\end{gathered}
$$

Substitution of Equations (5) and (6), taking into account of Equation (4) into Equation (3) gives:

$$
p\left(D_{Z}\right)=\left[\int_{-\infty}^{n \sigma_{d}} f_{X_{o Z}}(u) d u-\int_{-\infty}^{C-n \sigma_{r}} f_{X_{o Z}}(u) d u\right] \cdot\left[\int_{-\infty}^{-\left(C-n \sigma_{d}\right)} f_{X_{p Z}}(u) d u-\int_{-\infty}^{-n \sigma_{r}} f_{X_{p Z}}(u) d u\right]
$$

For a Gaussian distribution, Equation (7) can be rearranged in the following form [27]:

$$
p\left(D_{Z}\right)=\left[F_{X_{o Z}}(n)-F_{X_{o Z}}\left(\frac{C-n \sigma_{r}}{\sigma_{d}}\right)\right] \cdot\left[F_{X_{p Z}}\left(-\frac{C-n \sigma_{d}}{\sigma_{r}}\right)-F_{X_{p Z}}(-n)\right]
$$

where:

$$
\begin{aligned}
& F_{X_{o Z}}(n)=\frac{1}{\sqrt{2 \pi}} \int_{-\infty}^{n} e^{\frac{-u_{X_{o Z}}^{2}}{2}} d u_{X_{o Z}} ; \\
& F_{X_{p Z}}(n)=\frac{1}{\sqrt{2 \pi}} \int_{-\infty}^{n} e^{\frac{-u_{X_{p Z}}^{2}}{2}} d u_{X_{p Z} ;} ; \\
& F_{X_{o Z}}\left(\frac{C-n \sigma_{r}}{\sigma_{d}}\right)=\frac{1}{\sqrt{2 \pi}} \int_{-\infty}^{\frac{C-n \sigma_{r}}{\sigma_{d}}} e^{\frac{-u_{X_{o Z}}^{2}}{2} d u_{X_{o Z}} ;} \\
& F_{X_{p Z}}\left(\frac{C-n \sigma_{d}}{\sigma_{r}}\right)=\frac{1}{\sqrt{2 \pi}} \int_{-\infty}^{\frac{C-n \sigma_{d}}{\sigma_{r}}} e^{\frac{-u_{X_{p Z}}^{2}}{2}} d u_{X_{p Z}} ;
\end{aligned}
$$


$u_{X_{o Z}}=\frac{X_{o Z}}{\sigma_{d}} ; d u_{X_{o Z}}=\frac{d X_{o Z}}{\sigma_{d}} ; u_{X_{p Z}}=\frac{X_{p Z}}{\sigma_{r}} ; d u_{X_{p Z}}=\frac{d X_{p Z}}{\sigma_{r}}$

Equation (8) is based on the hypothesis that distribution of the deviations of the coulter and of the position of the plants along the row occurs according to a Laplace-Gauss distribution.

Finally, considering a Laplace-Gauss distribution, the distribution functions $F(X)$ can be expressed with sufficient degree of accuracy by the following [27]:

$$
F(X)=f(X)-\frac{r^{3}}{6} f^{(2)}(X)+\frac{r^{4}-3}{24} f^{(3)}(X)
$$

where $f(X)$ is theprobability density function; $f^{(j)}(X)$ is the $j$-th derivative of probability density function; $r^{3}, r^{4}$ are the main moments.

\section{Results and Discussion}

Expression of the values in the right-hand side of Equations (1) and (2) through design parameters $b$ and $l$ of the wide span tractor, as well as the heading angle $\varphi$, gives the following dependences of the transverse displacements of the coulter (working implement):

$$
\begin{aligned}
& \alpha_{\varphi}^{i}=l \sin \varphi+b(1-\cos \varphi) \\
& \alpha_{\varphi}^{e}=l \sin \varphi-b(1-\cos \varphi)
\end{aligned}
$$

where $b$ and $l$, respectively, are the distances from the longitudinal and transverse axes of the wide span tractor, which pass through its center to the coulter.

Equation (10) show that the inner and outer displacements of the same coulter are not equal to each other $\left(\alpha_{\varphi}^{i} \neq \alpha_{\varphi}^{e}\right)$ under the same angular deviation $\varphi$ of the wide span tractor. According to the Equations (10), Figure 3 shows that the difference between the inner and outer displacements of the peripheral working implements increases with the angle of deviation $\varphi$ and the design parameter $l$; the difference between displacements is negligible with small values of these parameters.

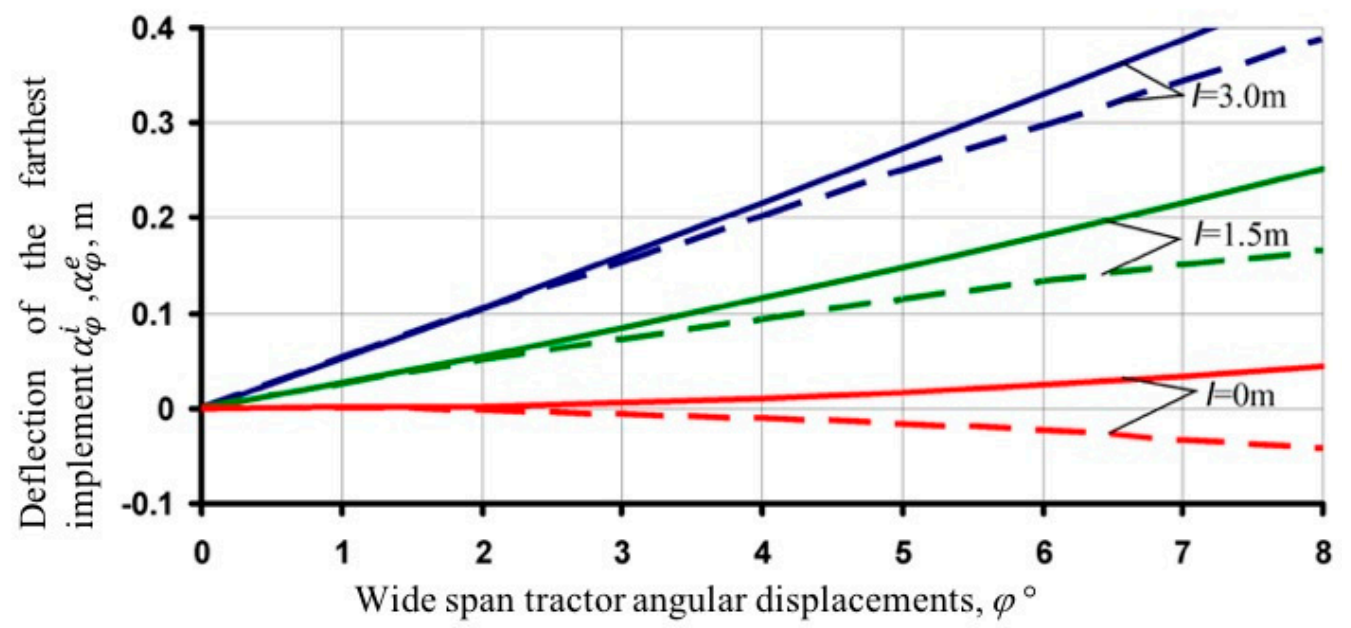

Figure 3. Inner $\alpha_{\varphi}^{i}(-)$ and outer $\alpha_{\varphi}^{e}(---)$ displacements of the peripheral working implement of the wide span tractor, depending on its angular deviation $\varphi$ for different values $l$.

It is extremely unprofitable to remove the implements from the transverse axis passing through the center of the wide span tractor. As the absolute value of the displacements of the implements increases, especially the inner displacements, the probability of damage to the plants by the implements also increases. Furthermore, the difference in shifts of wide span tractor implements affects the asymmetry of the operation. Therefore, if the displacements of the implements in opposite directions from a set motion trajectory are unequal to each other, then displacements of their aggregates are also unequal. 
It is not difficult to verify this if the value of the angle $\varphi$ is replaced by the standard deviation of the deflections in the right-hand member of the Equations (10). In this case, the standard deviation of implement displacements is obtained, which is determined by the standard angle deviations of the wide span tractor.

According to this, Equations (10) have the form:

$$
\begin{gathered}
\sigma_{\alpha_{\varphi}^{i}}=l \sin \sigma_{\varphi}+b\left(1-\cos \sigma_{\varphi}\right) \\
\sigma_{\alpha_{\varphi}^{e}}=l \sin \sigma_{\varphi}-b\left(1-\cos \sigma_{\varphi}\right)
\end{gathered}
$$

where:

$\sigma_{\alpha_{\varphi}^{i}}, \sigma_{\alpha_{\varphi}^{e}}-$ standard deviations of inner and outer displacements of the implement due to angular deviations of the wide span tractor;

$\sigma_{\varphi}$-standard deviation, pertinent to all angular deflections of the wide span tractor from the set trajectory of motion.

It is then possible to evaluate the absolute difference $\Delta \sigma_{\alpha_{\varphi}}$ between the standard deviations of the inner and outer displacements of the implement due to the corresponding standard deviations of the angular deflections of the wide span tractor:

$$
\Delta \sigma_{\alpha_{\varphi}}=\sigma_{\alpha_{\varphi}^{i}}-\sigma_{\alpha_{\varphi}^{e}}=2 b\left(1-\cos \sigma_{\varphi}\right),
$$

Equation (12) indicates that the absolute difference between the standard deviations of the inner and outer displacements of the implement caused by the angular deflections of the wide span tractor is essentially dependent on design parameter $b$ concerning its location on the tractor. The magnitude of $\Delta \sigma_{\alpha_{\varphi}}$ as a function of standard angular deviation of the wide span tractor for different values of $b$ is reported in Figure 4.

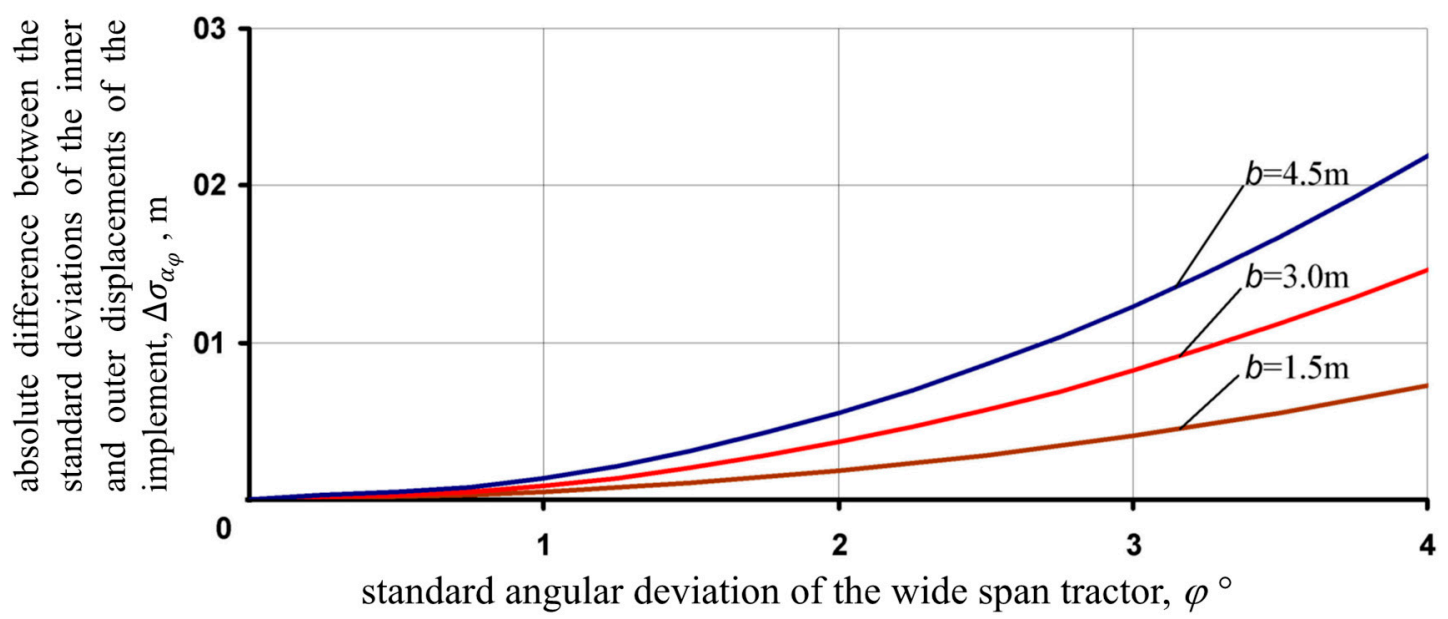

Figure 4. The absolute difference between the inner and outer standard deviations of displacements of the working implement depending on the standard deviations of the angular deflections of the wide span tractor, considering different values of $b$.

Figure 4 highlights that the design parameter $b$ significantly affects the magnitude of $\Delta \sigma_{\alpha_{\varphi}}$ caused by the angular deflections of the wide span tractor. Therefore, the wider the track of the wide span tractor, and consequently, the greater the distance from the longitudinal axis passing through the tractor center to the implement, the greater is the absolute difference between the standard deviation $\Delta \sigma_{\alpha_{\varphi}}$ of its inner and outer displacements. This is more noticeable with an increase in the angular standard deviation $\sigma_{\varphi}$, which considers the combination of all angular deviations of the wide span tractor from a set trajectory of motion. Therefore, to reduce the probability of damage to row plants 
by working implements, especially the more peripheral ones, the automatic system controlling wide span tractor movement must be able to reduce the magnitude of the angular variations from the set trajectory of movement.

The asymmetry of distribution of the working implement displacements can be taken into account for statistical evaluation of the damage to row plants. It is supposed that curves 1 and 3 of Figure 5 represent the probability density functions of the transverse displacements from the set trajectory of movement of the working implements located, respectively, on the left and right sides of the row, whereas curve 2 represents the probability density function concerning the position deflections of the plants from the row axis.

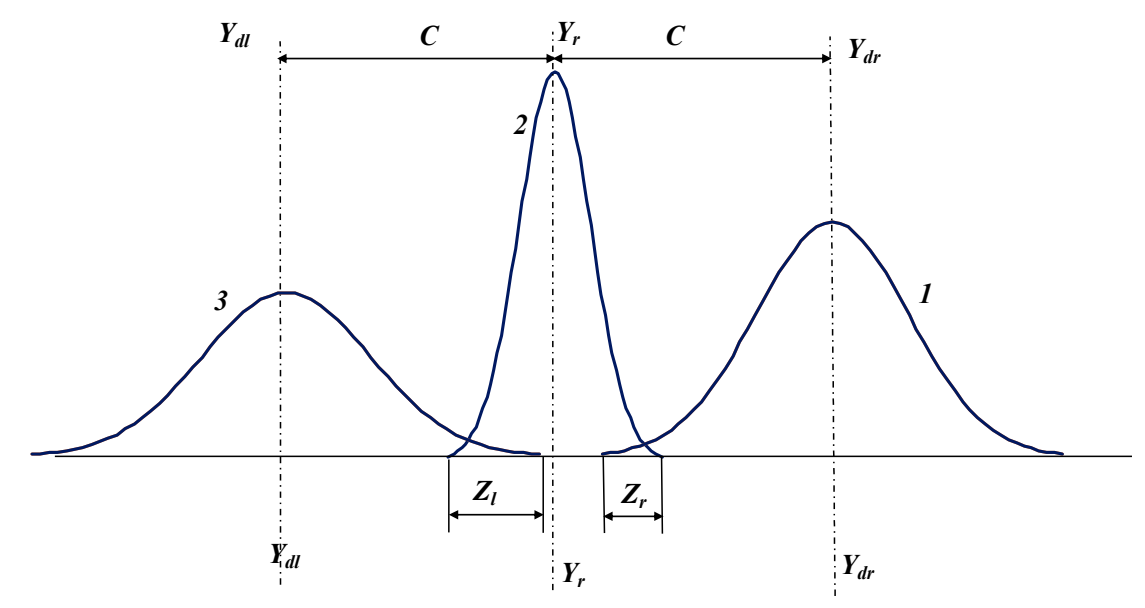

Figure 5. Probability density function of the transverse displacements from the set trajectory of movement of the right 1 and left 3 working implements located on both sides of the row and position deflections of the plants from the row axis 2.

The probabilities that the working implement to the left of the row is inside the $Z_{l}$ zone and the probabilities concerning the position of the working implement to the right of the row inside zone $Z_{r}$ differ from each other (zones $Z_{l}$ and $Z_{r}$, respectively, are different in Figure 4), i.e.:

$$
p\left(X_{o Z l}\right) \neq p\left(X_{o Z r}\right)
$$

Identically for the placement deflections of the plants from the row axis inside the $Z_{l}$ and $Z_{r}$ zones, respectively:

$$
p\left(X_{r Z l}\right) \neq p\left(X_{r Z r}\right)
$$

Considering Equation (3), the probability of plant damage inside zones $Z_{l}$ and $Z_{r}$, caused respectively by the left and right working implements, can be assessed by [27]:

$$
\begin{aligned}
& p\left(D_{Z l}\right)=p\left(X_{o Z l} \cdot X_{r Z l}\right)=p\left(X_{o Z l}\right) \cdot p\left(X_{r Z l}\right) \\
& p\left(D_{Z r}\right)=p\left(X_{o Z r} \cdot X_{r Z r}\right)=p\left(X_{o Z r}\right) \cdot p\left(X_{r Z r}\right)
\end{aligned}
$$

According to Equations (13) and (14), the right-hand sides of Equations (15) are unequal to each other, that is $p\left(D_{Z l}\right) \neq p\left(D_{Z r}\right)$ and then $C$ distance being equal, the probabilities of plant damage by cutting are dissimilar for the left and right working implements. This unlikeness increases with the increase in the asymmetry among the probability density functions pertinent/concerning to the transverse displacements of the working implements and the plant placement deviations from the row axis, respectively. The probability of plant damage by the working implements can be evaluated considering a Gaussian distribution [25]. Therefore, taking account of Equations (7), (8) and (9), 
Equations (15) can be rearranged to assess the probability of damage to row plants caused by the left (inner) and right (outer) working implements, respectively [27]:

$$
\begin{aligned}
p\left(D_{Z l}\right)=\left\{\left[f_{X_{o Z l}}(n)\right.\right. & \left.-\frac{r_{3}}{6} f_{X_{o Z l}}^{(2)}(n)+\frac{r_{4}-3}{24} f_{X_{o Z l}}^{(3)}(n)\right] \\
& \left.-\left[f_{X_{o Z l}}\left(\frac{C-n \sigma_{X r}}{\sigma_{X d}}\right)-\frac{r_{3}}{6} f_{X_{o Z l}}^{(2)}\left(\frac{C-n \sigma_{X r}}{\sigma_{X X}}\right)+\frac{r_{4}-3}{24} f_{X_{o Z l}}^{(3)}\left(\frac{C-n \sigma_{X r}}{\sigma_{X d}}\right)\right]\right\} \\
& \left\{\left[f_{X_{p Z}}\left(-\frac{C-n \sigma_{X d}}{\sigma_{X r}}\right)-\frac{r_{3}}{6} f_{X_{p Z}}^{(2)}\left(-\frac{C-n \sigma_{X d}}{\sigma_{X r}}\right)\right.\right. \\
& \left.+\frac{r_{4}-3}{24} f_{X_{p Z}}^{(3)}\left(-\frac{C-n \sigma_{X d}}{\sigma_{X r}}\right)\right] \\
& \left.-\left[f_{X_{p Z}}(-n)-\frac{r_{3}}{6} f_{X_{p Z}}^{(2)}(-n)+\frac{r_{4}-3}{24} f_{X_{p Z}}^{(3)}(-n)\right]\right\} \\
p\left(D_{Z r}\right)=\left\{\left[f_{X_{o Z r}}(-\right.\right. & \left.\left.\frac{C-n \sigma_{X X}}{\sigma_{X d}}\right)-\frac{r_{3}}{6} f_{X_{o Z r}}^{(2)}\left(-\frac{C-n \sigma_{X r}}{\sigma_{X d}}\right)+\frac{r_{4}-3}{24} f_{X_{o Z r}}^{(3)}\left(-\frac{C-n \sigma X r}{\sigma_{X d}}\right)\right] \\
& \left.-\left[f_{X_{o Z r}}(-n)-\frac{r_{3}}{6} f_{X_{o Z r}}^{(2)}(-n)+\frac{r_{4}-3}{24} f_{X_{o Z r}}^{(3)}(-n)\right]\right\} \\
& \cdot\left\{\left[f_{X_{p Z}}(n)-\frac{r_{3}}{6} f_{X_{p Z}}^{(2)}(n)+\frac{r_{4}-3}{24} f_{X_{p Z}}^{(3)}(n)\right]\right. \\
& \left.-\left[f_{X_{p Z}}\left(\frac{C-n \sigma_{X d}}{\sigma_{X r}}\right)-\frac{r_{3}}{6} f_{X_{p Z}}^{(2)}\left(\frac{C-n \sigma_{X d}}{\sigma_{X r}}\right)+\frac{r_{4}-3}{24} f_{X_{p Z}}^{(3)}\left(\frac{C-n \sigma_{X d}}{\sigma_{X r}}\right)\right]\right\}
\end{aligned}
$$

In order to analyze the probability of plant damage as a function of the size of safeguard zone $C$, it is supposed that the standard deviations of the displacements of the tractor's working implements and the plants' placement deflections from the row axis placements are approximately equal to $\sigma_{X d} \approx \sigma_{X r}$. This hypothesis is fairly well-founded if the the tractor's technological and automated driving systems ensure its stability when in movement [21-23]. Figure 6 shows the probability of damage to plants as a function of the value of safeguard zone $C$ for the inner and outer working implements, respectively. Figure 6 shows that with equal-sized safeguard zones $C$ on both sides of the row, the probability of damage by the corresponding working implements is different (Graph 1 and Graph 2, respectively, in Figure 6). For example, the probability of damage is $11.5 \%$ by the outer implement and $4.5 \%$ by the inner implement, considering a safeguard zone $C$ of $13 \mathrm{~cm}$ on each side of the row. This difference in the probability of plant damage is highly significant (greater than 150\%). Accordingly, to obtain the same probability of damage to the plants on both sides of the row, the right-hand and left-hand working implements of the wide-span tractor must be situated at different distances from the row axis. For example, to obtain a probability of damage below $2 \%$ on both sides of the row, it is necessary to place the peripherical working implements at distances of $0.13 \mathrm{~m}$ (inner working implements) and $0.16 \mathrm{~m}$ (outer working implements) respectively from the row axis (Figure 6).

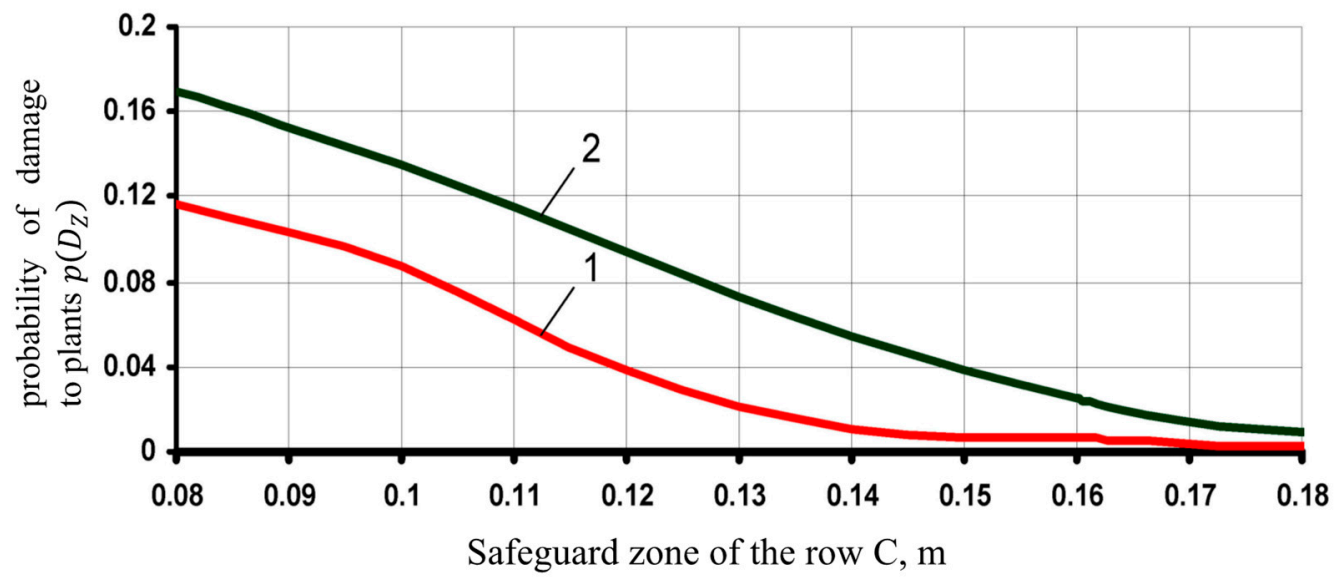

Figure 6. The probability of plant damage depending on the size of safeguard zone C: 1 -inner working implement; 2-outer working implement. 


\section{Conclusions}

1. Mathematical dependencies were developed, which make it possible to evaluate the transverse displacements of the working implements of a wide span tractor as a function of its design parameters, and the small angular deviations that unavoidably occur during operating conditions. In addition, a statistical methodology was developed for assessing the probability of damage to row plants and the suitable size of the safeguard zone to reduce this probability.

2. The magnitude of the inner and outer displacements of the working implements, as well as the absolute difference of the corresponding standard deviations, depends significantly on their longitudinal and transverse location relative to the center of the wide span tractor and is assessed by the magnitude of the angular deviations from the set trajectory of motion. For small values of these parameters, the magnitude of the transverse displacements of the working implements, and the absolute difference of their standard deviations, is negligible.

3. When placing cultivators as working implements for wide span tractor, the difference of their displacements should be taken into account. For working implements located outside the geometrical axis of the tractor, the size of the outer safeguard zone should be greater than the inner one. The probability of damage to row plants by the working implements can be reduced by automated control of wide span tractor movement in order to reduce all its angular deviations from the set trajectory of movement.

Author Contributions: Conceptualization and Methodology, V.B., V.A. and S.P.; Formal Analysis, Investigation and data curation, V.B., V.A. and V.K.; Writing-Original Draft Preparation, V.B., V.A. and L.N.; Writing-Review \& Editing, V.K., L.N. and S.P.; Supervision, V.B., V.A., S.P. and V.K.

Funding: This research received no external funding.

Acknowledgments: This research did not receive any specific grant from funding agencies in the public, commercial or not-for-profit sectors.

Conflicts of Interest: The authors declare no conflict of interest.

\section{References}

1. Arvidsson, J. Soil Compaction in Agriculture-from Soil Stress to Plant Stress; Swedish University of Agricultural Sciences: Uppsala, Sweden, 1997; p. 38.

2. Hamza, M.A.; Anderson, W.K. Soil compaction in cropping systems-A review of the nature, causes and possible solutions. Soil Tillage Res. 2005, 82, 121-145. [CrossRef]

3. Bulgakov, V.; Pascuzzi, S.; Santoro, F.; Anifantis, A.S. Mathematical Model of the Plane-Parallel Movement of the Self-Propelled Root-Harvesting Machine. Sustainability 2018, 10, 3614. [CrossRef]

4. Arvidsson, J.; Hakansson, I. A model for estimating crop yield losses caused by soil compaction. Soil Tillage Res. 1991, 20, 319-332. [CrossRef]

5. Hakansson, I.; Reeder, R.C. Subsoil compaction by vehicles with high axle load extent, persistence and crop response. Soil Tillage Res. 1994, 29, 277-304. [CrossRef]

6. Nevens, F.; Reheul, D. The consequences of wheel-induced soil compaction and subsoiling for silage maize on a sandy loam soil in Belgium. Soil Tillage Res. 2003, 70, 175-184. [CrossRef]

7. Raper, R.L. Agricultural traffic impacts on soil. J. Terramechanics 2005, 42, 259-280. [CrossRef]

8. Chamen, W.C.T. Controlled traffic farming-from worldwide research to adoption in Europe and its future prospects. Acta Technol. Agric. 2015, 18, 64-73. [CrossRef]

9. Kingwell, R.; Fuchsbichler, A. The whole-farm benefits of controlled traffic farming: An Australian appraisal. Agric. Syst. 2011, 104, 513-521. [CrossRef]

10. Chamen, W.C.T. Assessment of a Wide Span Vehicle (Gantry), and Soil and Cereal Crop Responses to Its Use in a Zero Traffic Regime. Soil Tillage Res. 1992, 24, 359-380. [CrossRef]

11. Bulgakov, V.; Adamchuk, V.; Kuvachov, V.; Nozdrovicky, L. Study of effectiveness of controlled traffic farming system and wide span self-propelled gantry-type machine. Res. Agr. Eng. 2018, 64, 1-7.

12. Onal, I. Controlled Traffic farming and Wide span tractors. J. Agric. Mach. Sci. 2012, 8, 353-364. 
13. Taylor, J.H. Reduction of traffic-induced soil compaction-Special issue. Soil Tillage Res. 1992, 24, $301-302$. [CrossRef]

14. Bulgakov, V.; Adamchuk, V.; Kuvachov, V.; Ivanovs, S. Research of possibilities for efficient use of wide span tractor (vehicle) for controlled traffic farming. In Proceedings of the Engineering for Rural Development: 16 International Scientific Conference, Jelgava, Latvia, 24-26 May 2017; Volume 16, pp. 281-287.

15. Bulgakov, V.; Adamchuk, V.; Kuvachov, V.; Ivanovs, S. Investigation of technological properties of wide span tractors for controlled traffic farming. In Proceedings of the Engineering for Rural Development: 16 International Scientific Conference, Jelgava, Latvia, 24-26 May 2017; Volume 16, pp. 303-308.

16. McHugha, A.D.; Tullberg, J.N.; Freebairn, D.M. Controlled traffic farming restores soil structure. Soil Tillage Res. 2009, 104, 164-172. [CrossRef]

17. Chamen, W.C.T.; Dowler, D.; Leede, P.R.; Longstaff, D.J. Design, Operation and Performance of a Gantry System: Experience in Arable Cropping. J. Agric. Eng. Res. 1994, 59, 45-60. [CrossRef]

18. Gasso, V.; Sørensen, C.A.G.; Oudshoorn, F.W.; Green, O. Controlled traffic farming: A review of the environmental impacts. Eur. J. Agron. 2013, 48, 66-73. [CrossRef]

19. Kuvachov, V. The study wide span tractor (vehicles) for controlled traffic farming. Mech. Agric. Conserv. Resour. 2017, 1, 15-18.

20. Kuvachov, V. Modelling of the flat parallel motion in horizontaal plane of the wide-span agri-machine during kinematic manner of its steering (Моделирование плоскопараллельного движения в горизонтальной плоскости ширококолейного агросредства при кинематическом способе его управления). Motrol 2015, $17,49-54$.

21. Kuvachov, V. Evaluation of the motion stability of the wide-span power-technological machines for mechanization of agricultural production. (Оценка устойчивости движения ширококолейных энерготехнологических средств механизации сельскохозяйственного производства). Sci. Alm. TDATU 2015, 5, 204-210.

22. Nadykto, V.; Kuvachov, V. Evaluation of the steering ability of the wide-span power-technological machines for mechanization of agricultural production. (Оценка управляемости движения ширококолейных энерготехнологических средств механизации сельскохозяйственного производства). Sci. Alm. TDATU 2016, 6, 99-110.

23. Adamchuk, V.; Bulgakov, V.; Holovach, I.; Kuvachov, V. Mathematical modelling of the movements of tractor working tools in controlled traffic farming. Agric. Sci. Pract. 2017, 4, 64-73. [CrossRef]

24. Bulgakov, V.; Pascuzzi, S.; Nadykto, V.; Ivanovs, S. A mathematical model of the plane-parallel movement of an asymmetric machine-and-tractor aggregate. Agriculture 2018, 8, 151. [CrossRef]

25. Bulgakov, V.; Pascuzzi, S.; Ivanovs, S.; Kaletnik, G.; Yanovich, V. Angular oscillation model to predict the performance of a vibratory ball mill for the fine grinding of grain. Biosyst. Eng. 2018, 171, 155-164. [CrossRef]

26. Khachatrian, K.A. Work Stability of Tillage Aggregates; Mashinostroenie: Moscow, Russia, 1974; 206p.

27. Mitropolskij, A.K. Technique of the Statistical Calculations (Техника статистических вычислений); Nauka Publisher: Moscow, Russia, 1971; 576p.

(C) 2019 by the authors. Licensee MDPI, Basel, Switzerland. This article is an open access article distributed under the terms and conditions of the Creative Commons Attribution (CC BY) license (http://creativecommons.org/licenses/by/4.0/). 